\title{
Corrigendum
}

\section{Alterations in brain structure in adults with anorexia nervosa and the impact of illness duration - CORRIGENDUM}

\author{
L. Fonville, V. Giampietro, S. C. R. Williams, A. Simmons and K. Tchanturia
}

doi:10.1017/S0033291713002389. Published online by Cambridge University Press, 27 September 2013.

The authors would like to amend an incorrect citation found on page 6 of the above article. The citation to Gaudio et al., 2011 should instead be to Gaudio \& Quattrocchi, 2012.

The corrected sentence is:

Body image distortion has been postulated to reflect dysfunctional processing of information (Williamson et al., 2004) and both lesional and functional studies have reported alterations in regions associated with visuospatial processing (Uher and Tresaure, 2005; Gaudio \& Quattrocchi, 2012).

The full reference to the citation is:

Gaudio S, Quattrocchi CC (2012). Neural basis of a multidimensional model of body image distortion in anorexia nervosa. Neuroscience and Biobehavioral Reviews 36, 1839-1847.

\section{Reference}

Fonville L, Giampietro V, Williams SCR, Simmons A, Tchanturia K. Alterations in brain structure in adults with anorexia nervosa and the impact of illness duration. Psychological Medicine, Published by Cambridge University Press, 27 September 2013. doi:10.1017/S0033291713002389. 